\title{
Synthesis and Crystal Structure of Alkynylplatinum(IV) Complex Containing the Terpyridine Ligand
}

\author{
Tsugiko Takase ${ }^{1}$ and Dai Oyama ${ }^{2}$ \\ ${ }^{1}$ Institute of Environmental Radioactivity, Fukushima University, 1 Kanayagawa, Fukushima 960-1296, Japan \\ ${ }^{2}$ Department of Industrial Systems Engineering, Cluster of Science and Engineering, Fukushima University, \\ 1 Kanayagawa, Fukushima 960-1296, Japan
}

Correspondence should be addressed to Dai Oyama; daio@sss.fukushima-u.ac.jp

Received 16 May 2014; Accepted 17 July 2014; Published 3 September 2014

Academic Editor: Mehmet Akkurt

Copyright (c) 2014 T. Takase and D. Oyama. This is an open access article distributed under the Creative Commons Attribution License, which permits unrestricted use, distribution, and reproduction in any medium, provided the original work is properly cited.

Reaction of square planar $\left[\mathrm{Pt}^{\mathrm{II}}(\mathrm{C} \equiv \mathrm{CPh})(\mathrm{tpy})\right]^{+}$(tpy $=2,2^{\prime}: 6^{\prime}, 2^{\prime \prime}$-terpyridine) with bromine at low temperature provides a general route for the synthesis of octahedral alkynyl(terpyridine)platinum(IV) complex. In this first example of alkynyl(terpyridine)platinum(IV) complex, the alkynyl group is situated in trans position relative to the central nitrogen atom of the terpyridine ligand, and the two bromido ligands are situated in trans positions; an X-ray structural analysis has been completed for trans(Br)$\left[\mathrm{Pt}^{\mathrm{IV}} \mathrm{Br}_{2}(\mathrm{C} \equiv \mathrm{CPh})(\mathrm{tpy})\right]^{+}$.

\section{Introduction}

Platinum(II) terpyridyl complexes with alkynyl ligands have attracted great interest in recent years due to their unique photophysics $[1,2]$ and their potential applications as photocatalysts for hydrogen evolution $[3,4]$ and molecular frameworks for light-to-chemical energy conversion [5]. On the other hand, there is a limited range of reported alkynylplatinum(IV) complexes [6-8]: there is no report on alkynylplatinum(IV) complex with terpyridine ligands. Although general oxidizing agents such as halogens and hydrogen peroxide are utilized for oxidation reactions of $\mathrm{Pt}^{\mathrm{II}}$ to $\mathrm{Pt}^{\mathrm{IV}}$ centers, halogens are particularly the most useful reagents [9, 10]. However, only one example for oxidation of alkynylplatinum(II) by halogens has been known in $\left[\mathrm{Pt}^{\mathrm{II}}\left(\mathrm{Me}_{2}\right.\right.$ bpy $)(\mathrm{C} \equiv \mathrm{C}-$ 4-tol $\left.)_{2}\right]$ by iodine to form $\left[\mathrm{Pt}^{\mathrm{IV}} \mathrm{I}_{2}\left(\mathrm{Me}_{2}\right.\right.$ bpy $\left.)(\mathrm{C} \equiv \mathrm{C} \text {-4-tol })_{2}\right]$ [6], due to instability of the $\mathrm{Pt}^{\mathrm{II}}$-alkynyl bond to halogencontaining oxidants [11]. Therefore, other procedures using 4-nitrophenyl azide and alkynyliodine(III) reagents as oxidants have been explored for oxidation of $\mathrm{Pt}^{\mathrm{II}}$ to $\mathrm{Pt}^{\mathrm{IV}}[7,8,12]$. In order to generalize about routes to
alkynylplatinum(IV) compounds by halogen-oxidation reaction without Pt-alkynyl bond breaking, we have optimized reaction conditions (the kind of oxidants and temperature) using alkynylplatinum(II) containing the terpyridine ligand as a prototype complex.

\section{Materials and Methods}

All chemicals employed here were used without further purification unless otherwise stated. All solvents purchased for organic synthesis were anhydrous and used without

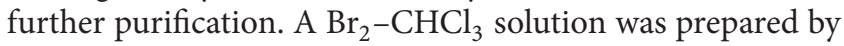
addition of 12 drops of $\mathrm{Br}_{2}$ to $10 \mathrm{~mL}$ of $\mathrm{CHCl}_{3}$ [10]. $\mathrm{A} \mathrm{Cl}_{2}-$ $\mathrm{CHCl}_{3}$ solution was prepared by a saturated $\mathrm{Cl}_{2}$ gas through $10 \mathrm{~mL}$ of $\mathrm{CHCl}_{3}$ for approximately $15 \mathrm{sec}$ [9]. The platinum(II) precursor $\left(\left[\mathrm{Pt}^{\mathrm{II}}(\mathrm{C} \equiv \mathrm{CPh})(\right.\right.$ tpy) $\left.] \mathrm{PF}_{6}\right)$ was prepared in accordance with the published method [2]. ${ }^{1} \mathrm{H}$ NMR spectra were recorded on a JEOL JMN-AL300 spectrometer $\left(25^{\circ} \mathrm{C}\right)$ operating at ${ }^{1} \mathrm{H}$ frequency of $300 \mathrm{MHz}$. ESI-MS data were measured on a Bruker Daltonics micrOTOF equipped with electrospray ionization (ESI) source and $\mathrm{CH}_{3} \mathrm{CN}$ was used 
TABLE 1: Crystallographic details for $\operatorname{trans}(\mathrm{Br})$ $\left[\mathrm{PtBr}_{2}(\mathrm{C} \equiv \mathrm{CPh})(\mathrm{tpy})\right] \mathrm{Br}$.

\begin{tabular}{lc}
\hline Empirical formula & $\mathrm{C}_{23} \mathrm{H}_{16} \mathrm{Br}_{3} \mathrm{~N}_{3} \mathrm{Pt}$ \\
$\mathrm{FW}$ & 769.20 \\
Temperature $(\mathrm{K})$ & $173(2)$ \\
$\lambda(\AA)$ & 0.71075 \\
Crystal system & Triclinic \\
Space group & $P-1$ \\
$a(\AA)$ & $7.2090(4)$ \\
$b(\AA)$ & $12.9921(6)$ \\
$c(\AA)$ & $13.1231(6)$ \\
$\alpha($ deg$)$ & $67.0477(14)$ \\
$\beta($ deg $)$ & $75.8967(15)$ \\
$\gamma($ deg $)$ & $78.1381(19)$ \\
$V\left(\AA^{3}\right)$ & $1089.25(9)$ \\
$Z$ & 2 \\
$\rho_{\text {calc }}\left(\mathrm{Mg} / \mathrm{m}^{3}\right)$ & 2.345 \\
$\mu(\mathrm{Mo} \mathrm{K} \alpha)\left(\mathrm{mm}^{-1}\right)$ & 11.950 \\
Number of reflections & 10839 \\
Unique reflections & 4955 \\
$\mathrm{GOF}\left(F^{2}\right)$ & 1.095 \\
$R_{\text {int }}$ & 0.0902 \\
$R 1^{\mathrm{a}}(I>2 \sigma)$ & 0.0486 \\
$w R 2^{\mathrm{b}}($ all data $)$ & 0.1210 \\
\hline${ }^{\mathrm{a}} R 1=\sum\left\|F_{o}|-| F_{c}\right\| / \sum\left|F_{o}\right|{ }^{\mathrm{b}} w R 2=\left\{\sum_{w}\left(F_{o}{ }^{2}-F_{c}{ }^{2}\right)^{2} / \sum_{w}\left(F_{c}{ }^{2}\right)^{2}\right\}^{1 / 2}$. \\
\end{tabular}

as the solvent. The instrument was operated at positive ion mode using $m / z$ range of $100-1000$. IR spectra were obtained using the $\mathrm{KBr}$ pellet method with a JASCO FT-IR 4100 spectrometer.

2.1. X-Ray Crystal Structure Determination. Single crystals of $1 \mathrm{Br}$ were obtained from a solution of the complex in $\mathrm{DMF} /$ diethyl ether. A brown crystal of $1 \mathrm{Br}$ with dimensions $0.15 \times 0.15 \times 0.03 \mathrm{~mm}$ was mounted on a glass fiber. All measurements were performed on a Rigaku R-AXIS RAPID diffractometer with graphite monochromated Mo K $\alpha$ radiation $(\lambda=0.71075 \AA)$. All calculations were conducted using the CrystalStructure program package [13] except for refinement, which was performed using SHELXL97 [14]. The structure was solved by direct methods using SIR92 program [15]. A numerical absorption correction (ABSCOR) [16] was applied to data. Aromatic hydrogen atoms were fixed at $\mathrm{C}-\mathrm{H}$ lengths of $0.95 \AA$ refined as riding, with $U_{\text {iso }}(\mathrm{H})=1.2 U_{\text {eq }}(\mathrm{C})$. Both the highest residual electron peak and the deepest hole are located within $1 \AA$ from atom Pt1. The crystallographic data are summarized in Table 1 and the geometrical parameters are summarized in Table 2. The crystal data for $1 \mathrm{Br}$ has been deposited with Cambridge Crystallographic Data Centre as supplementary publication number CCDC-1014039.
TABLE 2: Geometrical parameters.

(a) Selected bond lengths and angles $\left(\AA,^{\circ}\right)$

\begin{tabular}{lccc}
\hline Pt1-Br1 & $2.4498(12)$ & C1-C2 & $1.059(17)$ \\
Pt1-Br2 & $2.4644(12)$ & N1-Pt1-N2 & $80.8(4)$ \\
Pt1-N1 & $2.041(10)$ & N2-Pt1-N3 & $80.2(4)$ \\
Pt1-N2 & $1.976(9)$ & Pt1-C1-C2 & $175.3(12)$ \\
Pt1-N3 & $2.030(11)$ & C1-C2-C3 & $174.4(14)$ \\
Pt1-C1 & $2.054(10)$ & Br1-Pt1-Br2 & $178.46(5)$ \\
\hline
\end{tabular}

(b) Interatomic distances $(\AA)$ for intermolecular $\pi-\pi$ interactions

\begin{tabular}{lr}
\hline $\mathrm{C} 2 \cdots \mathrm{C} 22^{\mathrm{i}}$ & $3.299(15)$ \\
$\mathrm{C} 3 \cdots \mathrm{C} 21^{\mathrm{i}}$ & $3.373(15)$ \\
$\mathrm{C} 3 \cdots \mathrm{C} 22^{\mathrm{i}}$ & $3.302(15)$ \\
$\mathrm{C} 4 \cdots \mathrm{C} 23^{\mathrm{ii}}$ & $3.366(17)$ \\
$\mathrm{C} 5 \cdots \mathrm{C} 20^{\mathrm{i}}$ & $3.290(17)$ \\
$\mathrm{C} 5 \cdots \mathrm{C} 22^{\mathrm{ii}}$ & $3.362(17)$ \\
$\mathrm{C} 5 \cdots \mathrm{C} 23^{\mathrm{ii}}$ & $3.256(16)$ \\
$\mathrm{C} 8 \cdots \mathrm{C} 21^{\mathrm{i}}$ & $3.374(18)$ \\
\hline Symmetry operators: ${ }^{\mathrm{i}}-x+1,-y+1,-z+1{ }^{\mathrm{ii}}-x+2,-y+1,-z+1$.
\end{tabular}

(c) Hydrogen-bond geometry $\left(\AA,{ }^{\circ}\right)$

\begin{tabular}{lcccc}
\hline$D-\mathrm{H} \cdots A$ & $D-\mathrm{H}$ & $\mathrm{H} \cdots A$ & $D \cdots A$ & $D-\mathrm{H} \cdots A$ \\
\hline $\mathrm{C} 4-\mathrm{H} 1 \cdots \mathrm{Br} 1^{\mathrm{i}}$ & 0.95 & 2.84 & $3.688(14)$ & 149 \\
$\mathrm{C} 11-\mathrm{H} 8 \cdots \mathrm{Br} 1^{\mathrm{ii}}$ & 0.95 & 2.86 & $3.761(13)$ & 160 \\
$\mathrm{C} 22-\mathrm{H} 15 \cdots \mathrm{Br} 1^{\mathrm{i}}$ & 0.95 & 3.34 & $3.836(14)$ & 115 \\
$\mathrm{C} 23-\mathrm{H} 16 \cdots \mathrm{Br}^{\mathrm{i}}$ & 0.95 & 2.80 & $3.576(13)$ & 140 \\
$\mathrm{C} 4-\mathrm{H} 1 \cdots \mathrm{Br} 2^{\mathrm{iii}}$ & 0.95 & 3.49 & $4.072(13)$ & 122 \\
$\mathrm{C} 5-\mathrm{H} 2 \cdots \mathrm{Br} 2^{\mathrm{iii}}$ & 0.95 & 3.17 & $3.922(14)$ & 137 \\
$\mathrm{C} 16-\mathrm{H} 11 \cdots \mathrm{Br} 2^{\text {iv }}$ & 0.95 & 2.87 & $3.702(14)$ & 147 \\
$\mathrm{C} 10-\mathrm{H} 7 \cdots \mathrm{Br} 2^{\mathrm{v}}$ & 0.95 & 2.94 & $3.733(13)$ & 142 \\
$\mathrm{C} 8-\mathrm{H} 5 \cdots \mathrm{Br} 3^{\mathrm{ii}}$ & 0.95 & 3.12 & $3.758(13)$ & 126 \\
$\mathrm{C} 9-\mathrm{H} 6 \cdots \mathrm{Br} 3^{\mathrm{ii}}$ & 0.95 & 3.14 & $3.738(11)$ & 122 \\
$\mathrm{C} 22-\mathrm{H} 15 \cdots \mathrm{Br} 3^{\mathrm{vi}}$ & 0.95 & 3.20 & $3.872(12)$ & 129 \\
$\mathrm{C} 10-\mathrm{H} 7 \cdots \mathrm{Br} 3^{\mathrm{ii}}$ & 0.95 & 3.12 & $3.718(13)$ & 122 \\
$\mathrm{C} 12-\mathrm{H} 9 \cdots \mathrm{Br} 3$ & 0.95 & 3.19 & $3.945(13)$ & 138 \\
$\mathrm{C} 15-\mathrm{H} 10 \cdots \mathrm{Br} 3$ & 0.95 & 2.89 & $3.597(13)$ & 132 \\
$\mathrm{C} 6-\mathrm{H} 3 \cdots \mathrm{Br} 3^{\mathrm{vii}}$ & 0.95 & 3.32 & $3.943(13)$ & 125 \\
$\mathrm{C} 17-\mathrm{H} 12 \cdots \mathrm{Br} 3^{\mathrm{viii}}$ & 0.95 & 2.89 & $3.819(15)$ & 166 \\
$\mathrm{C} 21-\mathrm{H} 14 \cdots \mathrm{Br} 3^{\text {vi }}$ & 0.95 & 3.28 & $3.909(13)$ & 126 \\
\hline
\end{tabular}

Symmetry operators: ${ }^{\mathrm{i}}-x+1,-y+1,-z+1 ;{ }^{\mathrm{ii}}-x,-y+1,-z+2 ;{ }^{\mathrm{iii}}-x+2$, $-y+1,-z+1{ }^{\mathrm{iv}}-x+1,-y,-z+2 ;^{\mathrm{v}}-x+1,-y+1,-z+2{ }^{\mathrm{vi}} x+1, y$, $z-1{ }^{\text {vii }} x+1, y+1, z-1$; $^{\text {viii }}-x,-y,-z+2$.

2.2. Preparation of trans $(\mathrm{Br})-\left[\mathrm{PtBr} r_{2}(\mathrm{C} \equiv \mathrm{CPh})(t \mathrm{tpy})\right] \mathrm{Br}(\mathbf{1 B r})$. An orange suspension of $[\mathrm{Pt}(\mathrm{C} \equiv \mathrm{CPh})(\mathrm{tpy})] \mathrm{PF}_{6} \quad(30 \mathrm{mg}$, $0.044 \mathrm{mmol})$ in acetonitrile $(10 \mathrm{~mL})$ was stirred at $-20^{\circ} \mathrm{C}$ for $30 \mathrm{~min}$. Addition of $\mathrm{Br}_{2}-\mathrm{CHCl}_{3}$ (70 drops) to the suspension resulted in a homogeneous solution. The mixture was further stirred at $-20^{\circ} \mathrm{C}$ for $2 \mathrm{~h}$; during this time some light brown solids gradually appeared out of the solution. The product was collected by filtration, washed with diethyl ether, and then dried in vacuo $(25 \mathrm{mg}, 73 \%)$. $\mathrm{ESI}^{+}-\mathrm{MS}: m / z=690\left([\mathrm{M}]^{+}\right), 529$ $\left([\mathrm{M}-2 \mathrm{Br}]^{+}\right) .{ }^{1} \mathrm{H}$ NMR $\left(\mathrm{DMSO}-d_{6}\right): \delta 9.29\left(d\right.$ with broad ${ }^{195} \mathrm{Pt}$ 


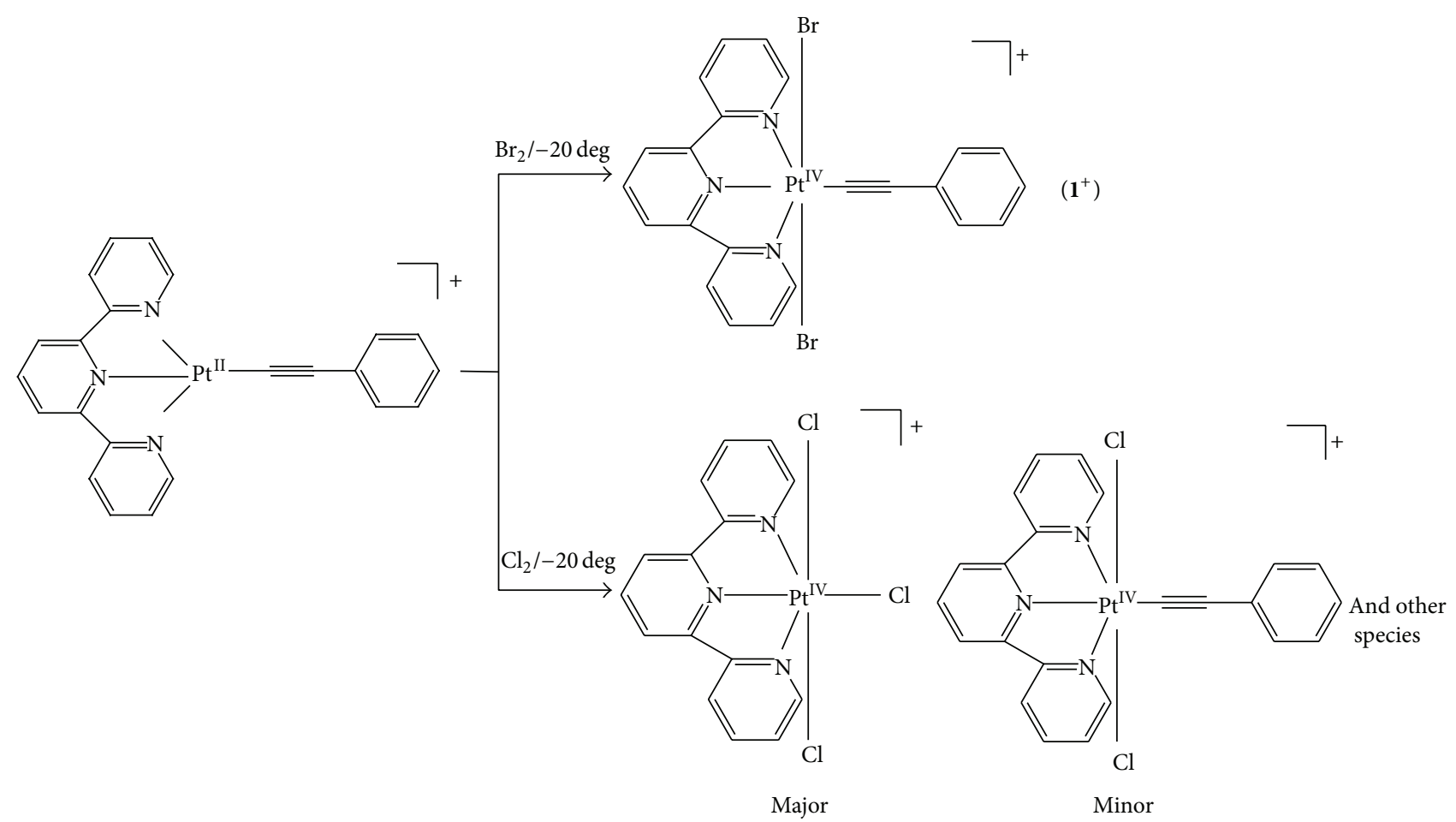

SCHEme 1: Synthetic route for platinum(IV) complexes in this study.

satellites, $2 \mathrm{H}), 9.13-8.88(m, 5 \mathrm{H}), 8.70(t, 2 \mathrm{H}), 8.20(t, 2 \mathrm{H})$, $7.65(d, 2 \mathrm{H}), 7.47-7.35(m, 3 \mathrm{H})$. IR: $v(\mathrm{C} \equiv \mathrm{C}) 2165 \mathrm{~cm}^{-1}$.

\section{Results and Discussion}

3.1. Synthesis of $\operatorname{trans}(B r)-\left[P t B r_{2}(C \equiv C P h)(t p y)\right] B r$. The synthetic route for the formation of platinum(IV) terpyridyl complexes is summarized in Scheme 1. Addition of $\mathrm{Br}_{2}-$ $\mathrm{CHCl}_{3}$ solution to $\left[\mathrm{Pt}^{\mathrm{II}}(\mathrm{C} \equiv \mathrm{CPh})(\text { tpy })\right]^{+}$in acetonitrile at $-20^{\circ} \mathrm{C}$ gave $\left[\mathrm{Pt}^{\mathrm{IV}} \mathrm{Br}_{2}(\mathrm{C} \equiv \mathrm{CPh})(\mathrm{tpy})\right]^{+}\left(\mathbf{1}^{+}\right)$as light brown solid in $73 \%$ yield. When this reaction was performed at room temperature, $\mathbf{1}^{+}$was produced but a small quantity of the alkynyl dissociated species was detected. In the same condition, however, addition of $\mathrm{Cl}_{2}-\mathrm{CHCl}_{3}$ solution gave some impurities in addition to $\left[\mathrm{Pt}^{\mathrm{IV}} \mathrm{Cl}_{3}(\mathrm{tpy})\right]^{+}(\mathrm{m} / z=534$, major product) and $\left[\mathrm{Pt}^{\mathrm{IV}} \mathrm{Cl}_{2}(\mathrm{C} \equiv \mathrm{CPh})(\mathrm{tpy})\right]^{+}(\mathrm{m} / z=600$, minor product) (Scheme 1). These results indicate that the $\mathrm{Pt}-$ $\mathrm{C}$ bond in $[\mathrm{Pt}(\mathrm{C} \equiv \mathrm{CPh})(\mathrm{tpy})]^{+}$is influenced by the strength of oxidants and reaction temperatures: milder conditions $\left(\mathrm{Br}_{2}\right.$ as an oxidant and low temperature) are required for bond retention of the Pt-alkynyl moiety.

3.2. Characterization of $\operatorname{trans}(\mathrm{Br})-\left[\mathrm{PtBr} r_{2}(\mathrm{C} \equiv \mathrm{CPh})(\mathrm{tpy})\right]^{+}$. The identities of the complex $\mathbf{1}^{+}$have been confirmed by IR spectroscopy, ${ }^{1} \mathrm{H}$ NMR spectroscopy, and ESImass spectroscopy. The molecular structure of $1 \mathrm{Br}$ has also been determined. To the best of our knowledge, this study demonstrates the first crystal structure of an alkynylplatinum(IV) with the terpyridine ligand.

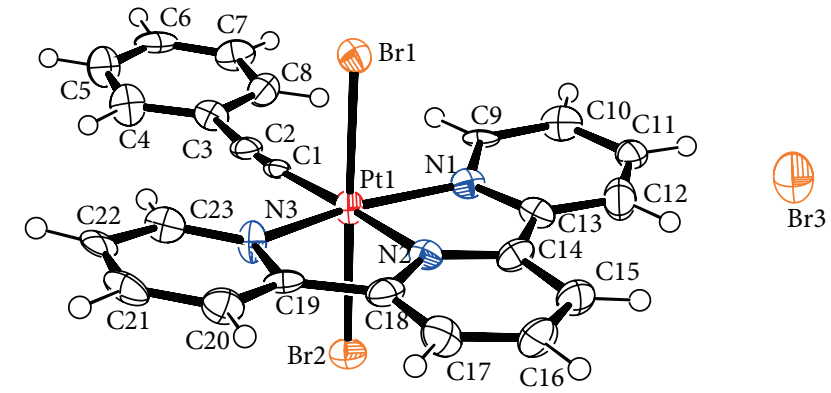

Figure 1: The molecular structure of $\operatorname{trans}(\mathrm{Br})$ $\left[\mathrm{PtBr}_{2}(\mathrm{C} \equiv \mathrm{CPh})(\mathrm{tpy})\right] \mathrm{Br}(\mathbf{1 B r})$, showing the atom-labeling scheme and displacement ellipsoids drawn at the $50 \%$ probability level.

The IR spectrum of $1 \mathrm{Br}$ exhibited $\nu(\mathrm{C} \equiv \mathrm{C})$ absorption at $2165 \mathrm{~cm}^{-1}$, which is $40 \mathrm{~cm}^{-1}$ higher than that of $\left[\mathrm{Pt}{ }^{\mathrm{II}}(\mathrm{C} \equiv \mathrm{CPh})(\mathrm{tpy})\right]^{+}[17]$. The ${ }^{1} \mathrm{H}$ NMR spectra of $\mathbf{1}^{+}$showed resonances at more downfield regions compared to the corresponding $\mathrm{Pt}^{\mathrm{II}}$ complex [17]. For example, the doublet signals of $6,6^{\prime \prime}$-positions in terpyridine ligand of $1^{+}$appeared at $9.29 \mathrm{ppm}$, whereas those of $\left[\mathrm{Pt}^{\mathrm{II}}(\mathrm{C} \equiv \mathrm{CPh})(\mathrm{tpy})\right]^{+}$appeared at $9.10 \mathrm{ppm}$, indicating a lowering of the electron density on a Pt center.

The molecular structure of $1 \mathrm{Br}$ is shown in Figure 1 with atom-labeling scheme. The complex consists of a distorted octahedral geometry around the $\mathrm{Pt}^{\mathrm{IV}}$ center with three nitrogen atoms of the terpyridine ligand, two bromido ligands in trans positions, and an alkynyl group in trans position relative 


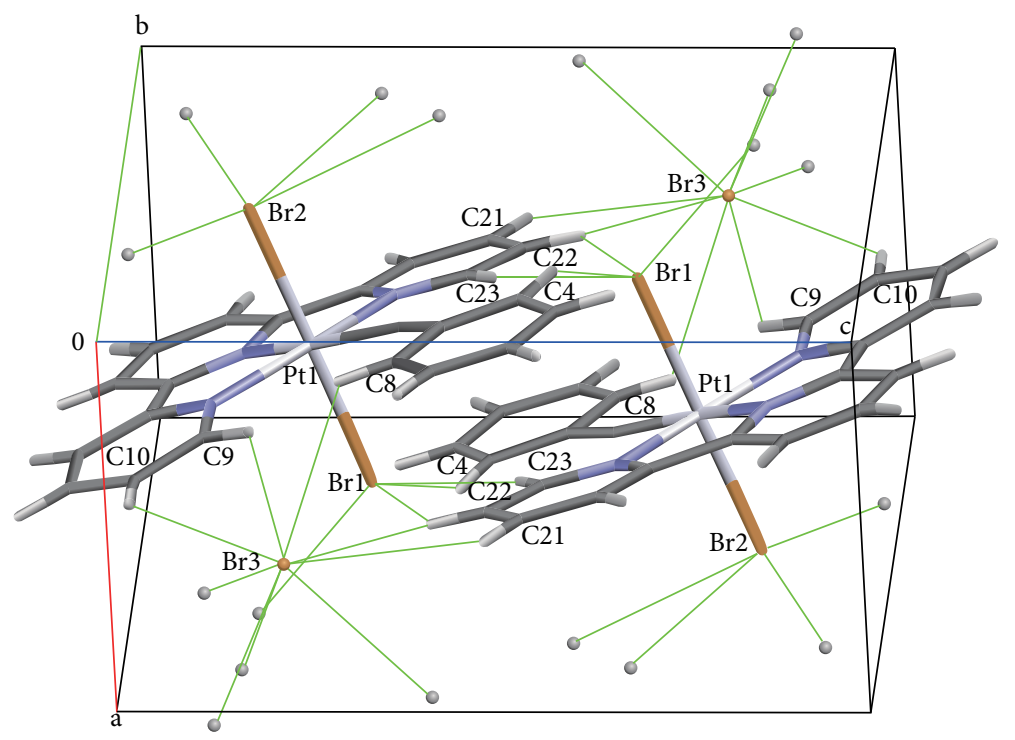

Figure 2: Packing diagram. The green lines denote intermolecular hydrogen bonds.

to the central nitrogen atom $\left(1^{\prime}\right.$-position) of the terpyridine ligand. The terpyridine ligand is coordinated in a planar tridentate fashion with the central nitrogen atom closest to the $\mathrm{Pt}^{\mathrm{IV}}$ atom. As shown in Table 2(a), the bond lengths of Pt$\mathrm{N}$ are comparable to the precursor platinum(II) terpyridine complex [2]. Additionally, the Pt1-C1-C2 and C1-C2-C3 fragments are nearly linear with bond angles of $175.3(12)^{\circ}$ and $174.4(14)^{\circ}$, respectively. However, both the $\mathrm{Pt}-\mathrm{C}$ and the $\mathrm{C} \equiv \mathrm{C}$ bond lengths (2.054(10) and 1.059(17) $\AA$, resp.) are different from those of the corresponding $\mathrm{Pt}^{\mathrm{II}}$ complex (1.98(1) and 1.19(1) $\AA$, resp.) [2]. In the crystal, the cation of $1 \mathrm{Br}$ features intermolecular $\pi-\pi$ stacking between the phenyl group of the alkynyl ligand and the terpyridine ligand, as represented by the shortest contact of 3.256(16) $\AA$ for C5 . . C23 (Table 2(b)). The phenyl ring of the alkynyl ligand is almost parallel to the plane of Pt-terpyridine with a dihedral angle of $5.438^{\circ}$, indicating the formation of a face-to-face $\pi-\pi$ interaction (Figure 2). In addition, there are a number of intermolecular weak $\mathrm{C}-\mathrm{H} \cdots \mathrm{Br}$ interactions in the crystal as illustrated in Figure 2. These interactions help to stabilize the structure.

\section{Conclusions}

In summary, we have prepared an alkynylplatinum(IV) complex by simple oxidation of the corresponding alkynylplatinum(II) one. It is anticipated that the successful route described here provides a useful methodology to obtain a variety of platinum(IV) complexes with a wide range of alkynyl ligands.

\section{Supplementary Data}

Complete lists of positional and isotropic displacement coefficients for hydrogen atoms and anisotropic displacement coefficients for the nonhydrogen atoms, bond lengths and angles, and torsion angles are listed as supplementary material available on line at http://dx.doi.org/10.1155/2014/280247.

\section{Conflict of Interests}

The authors declare that there is no conflict of interests regarding the publication of this paper.

\section{Acknowledgment}

$\mathrm{H}$. Watanabe is thanked for experimental assistance at an early stage of the project.

\section{References}

[1] K. M.-C. Wong and V. W.-W. Yam, "Self-assembly of luminescent alkynylplatinum(II) terpyridyl complexes: modulation of photophysical properties through aggregation behavior," Accounts of Chemical Research, vol. 44, no. 6, pp. 424-434, 2011.

[2] V. W.-W. Yam, R. P.-L. Tang, K. M.-C. Wong, and K.-K. Cheung, "Synthesis, luminescence, electrochemistry, and ionbinding studies of platinum(II) terpyridyl acetylide complexes," Organometallics, vol. 20, no. 22, pp. 4476-4482, 2001.

[3] R. Narayana-Prabhu and R. H. Schmehl, "Photoinduced electron-transfer reactions of platinum(II) terpyridyl acetylide complexes: reductive quenching in a hydrogen-generating system," Inorganic Chemistry, vol. 45, no. 11, pp. 4319-4321, 2006.

[4] P. Du, J. Schneider, P. Jarosz, and R. Eisenberg, "Photocatalytic generation of hydrogen from water using a platinum(II) terpyridyl acetylide chromophore," Journal of the American Chemical Society, vol. 128, no. 24, pp. 7726-7727, 2006.

[5] S. Chakraborty, T. J. Wadas, H. Hester, C. Flaschenreim, R. Schmehl, and R. Eisenberg, "Synthesis, structure, characterization, and photophysical studies of a new platinum terpyridylbased triad with covalently linked donor and acceptor groups," Inorganic Chemistry, vol. 44, no. 18, pp. 6284-6293, 2005. 
[6] S. L. James, M. Younus, P. R. Raithby, and J. Lewis, "Platinum bis-acetylide complexes with the $4,4^{\prime}$-dimethyl-2,2' -bipyridyl ligand," Journal of Organometallic Chemistry, vol. 543, no. 1-2, pp. 233-235, 1997.

[7] A. J. Canty and T. Rodemann, "Entry to alkynylplatinum(IV) chemistry using hypervalent iodine(III) reagents, and the synthesis of triphenyl $\left\{4,4^{\prime}\right.$-bis(tert-butyl)-2,2' -bipyridine $\}$ iodoplatinum(IV)," Inorganic Chemistry Communications, vol. 6, no. 11, pp. 1382-1384, 2003.

[8] A. J. Canty, T. Rodemann, B. W. Skelton, and A. H. White, "Synthesis and structure of alkynylplatinum(IV) complexes containing the pincer group [2,6-(dimethylaminomethyl)phenyl- $N, C$, $\mathrm{N}^{-}$," Inorganic Chemistry Communications, vol. 8, no. 1, pp. 5557, 2005.

[9] L. M. Mink, M. L. Neitzel, L. M. Bellomy et al., "Platinum(II) and platinum(IV) porphyrin complexes: synthesis, characterization, and electrochemistry," Polyhedron, vol. 16, no. 16, pp. 2809-2817, 1997.

[10] L. M. Mink, J. W. Voce, J. E. Ingersoll et al., "Platinum(IV) tetraphenylporphyrin dibromide complexes: synthesis, characterization, and electrochemistry," Polyhedron, vol. 19, no. 9, pp. 1057-1062, 2000.

[11] S. Back, R. A. Gossage, M. Lutz et al., "Bis - ortho chelated diaminoaryl platinum compounds with $\sigma$-acetylene substituents. Investigations into their stability and subsequent construction of multimetallic systems. The crystal structure of $\left[\left(\mu^{2}-\left[\left(\eta^{2}-\mathrm{NCN}\right) \mathrm{Pt}\left(\eta^{1}-\mathrm{CO}\right) \mathrm{C} \equiv \mathrm{CSiMe}_{3}\right]\right) \mathrm{Co}_{2}(\mathrm{CO})_{6}\right](\mathrm{NCN}$ = 2,6-bis $[($ dimethyl(amino)methyl)phenyl]," Organometallics, vol. 19, no. 17, pp. 3296-3304, 2000.

[12] A. Bayler, A. J. Canty, J. H. Ryan, B. W. Skelton, and A. H. White, "Arylation of palladium(II) and platinum(II) by diphenyliodonium triflate to form metal(IV) species, and a structural analysis of an isomer of $\mathrm{PtIMe}_{2} \mathrm{Ph}$ (bpy) (bpy $=2,2^{\prime}-$ bipyridine)," Inorganic Chemistry Communications, vol. 3, no. 11, pp. 575-578, 2000.

[13] CrystalStructure, Version 4.0, Rigaku Corporation, Tokyo, Japan, 2010.

[14] G. M. Sheldrick, "A short history of SHELX," Acta Crystallographica A: Foundations of Crystallography, vol. 64, part 1, pp. 112-122, 2008.

[15] A. Altomare, G. Cascarano, C. Giacovazzo et al., "SIR92-a program for automatic solution of crystal structures by direct methods," Journal of Applied Crystallography, vol. 27, no. 3, pp. 435-436, 1994.

[16] ABSCOR, Rigaku Corporation, Tokyo, Japan, 1995.

[17] V. W.-W. Yam, K. H.-Y. Chan, K. M.-C. Wong, and N. Zhu, "Luminescent platinum(II) terpyridyl complexes: effect of counter ions on solvent-induced aggregation and color changes," Chemistry - A European Journal, vol. 11, no. 15, pp. 4535-4543, 2005. 

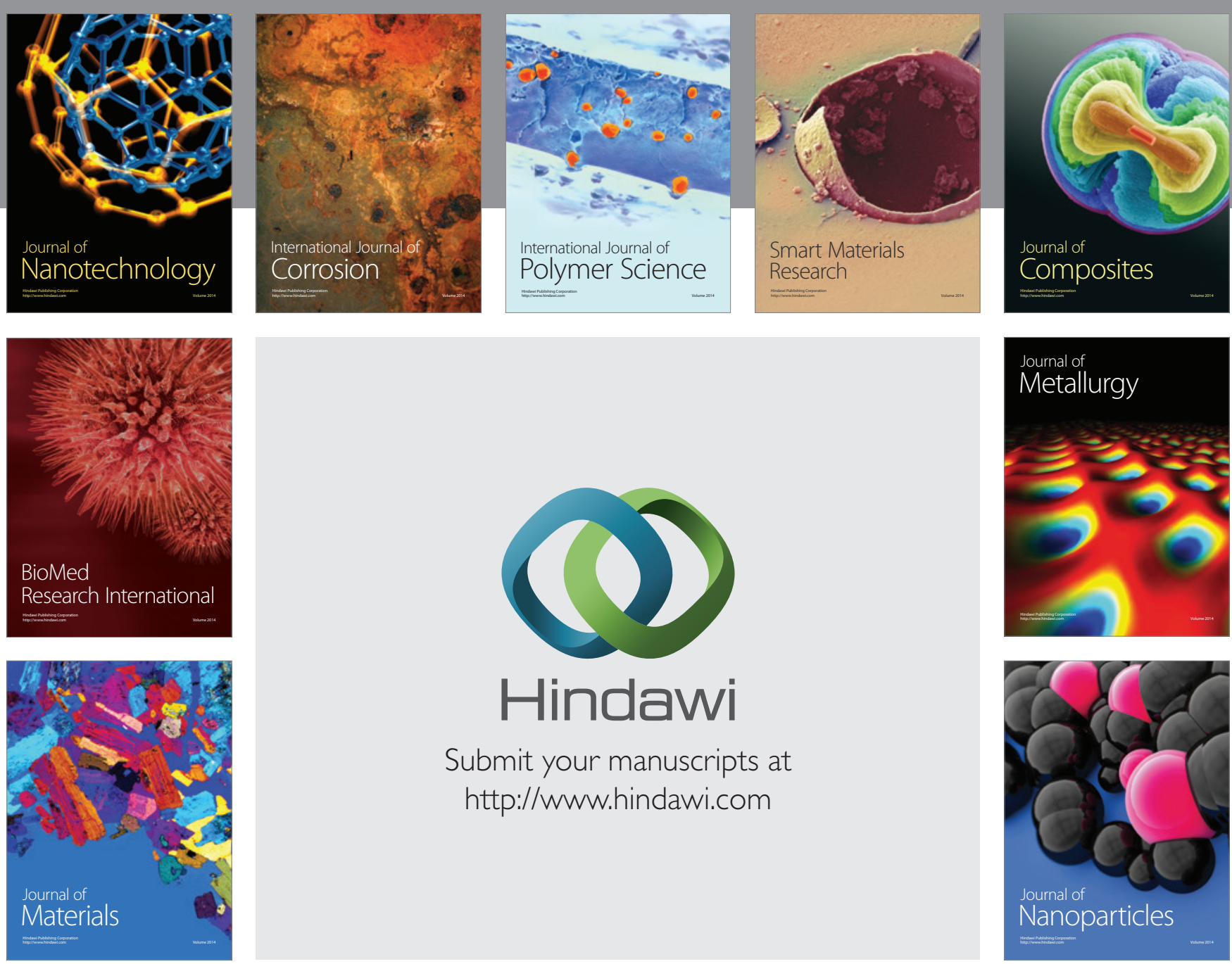

Submit your manuscripts at http://www.hindawi.com
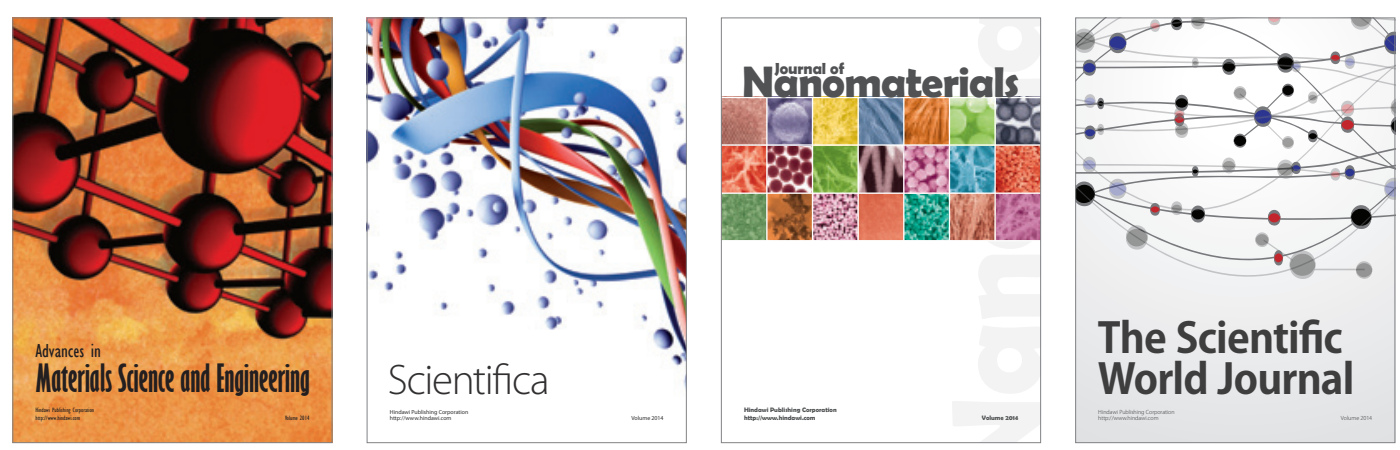

\section{The Scientific World Journal}
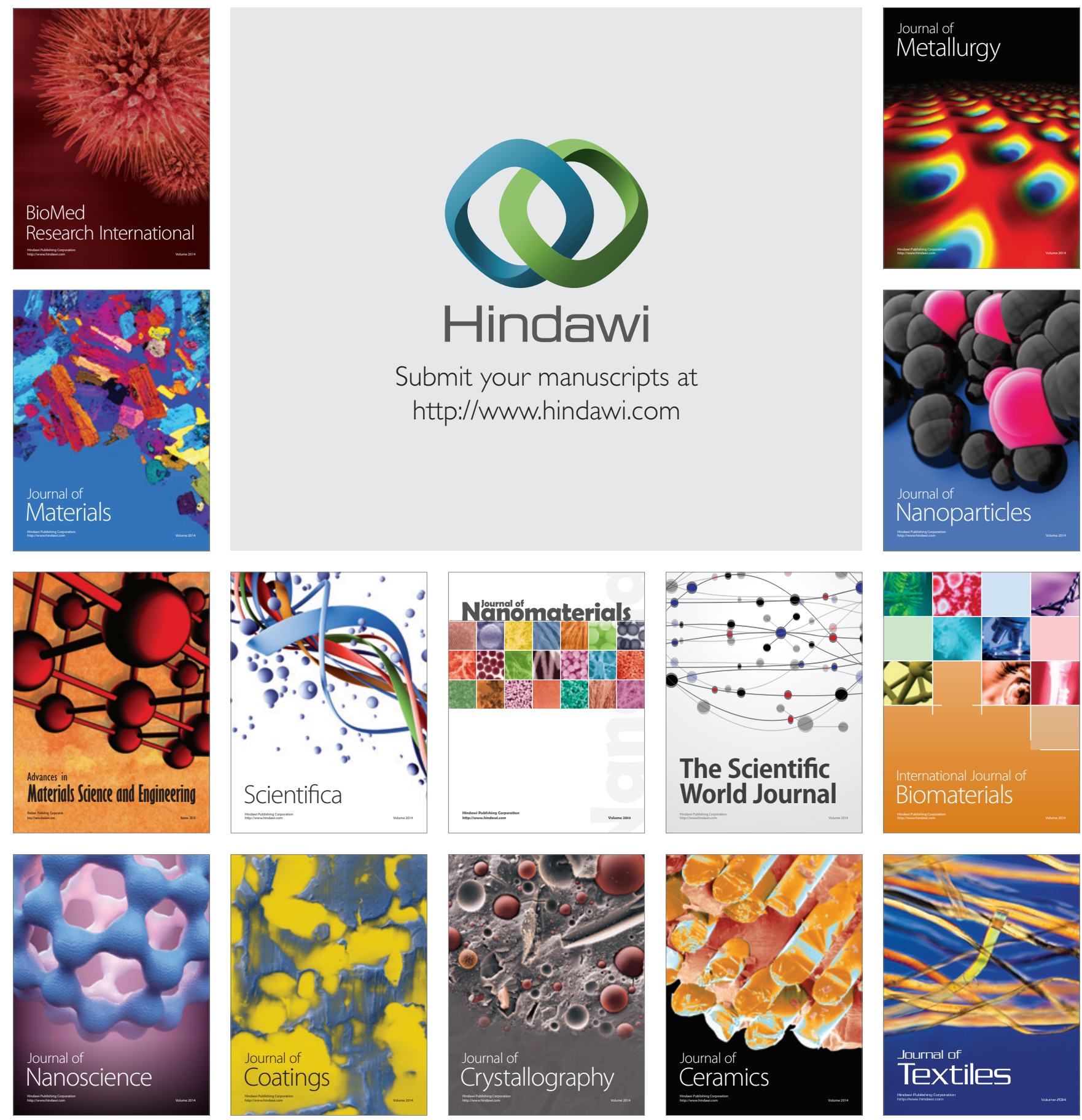